\title{
Tuning Antisite Defect Density in Perovskite-BaLiF 3 via Cycling between Ball Milling and Heating
}

\author{
Andre Düvel ${ }^{(1)^{*}}$, Lucy M. Morgan ${ }^{(1)}$, Giannantonio Cibin ${ }^{(2)}$, David Pickup ${ }^{(1)}$, Alan V. Chadwick ${ }^{(1)}$, Paul \\ Heitjans $^{(3)}$, Dean C. Sayle ${ }^{(1)^{*}}$ \\ (1) School of Physical Sciences, University of Kent, CT2 7NH, U.K. \\ (2) Diamond Light Source, Harwell Science and Innovation Campus, Didcot, Oxfordshire OX11 0DE, U.K. \\ (3) Institute of Physical Chemistry and Electrochemistry, Leibniz University Hannover, Callinstr. 3-3a, 30167 Hannover, Germany.
}

\section{ABSTRACT:}

The defect density of a material is central to its properties. Here, we show, employing EXAFS measurements and MD simulation, how the $\mathrm{Ba}-\mathrm{Li}$ antisite defect density of perovskite-structured $\mathrm{BaLiF}_{3}$ nanoparticles can be tuned. In particular, we show that ball milling reduces the defect content. Conversely, thermal annealing increases the defect density. The work represents a first step towards tailoring the properties of a material, via defect tuning postsynthesis.

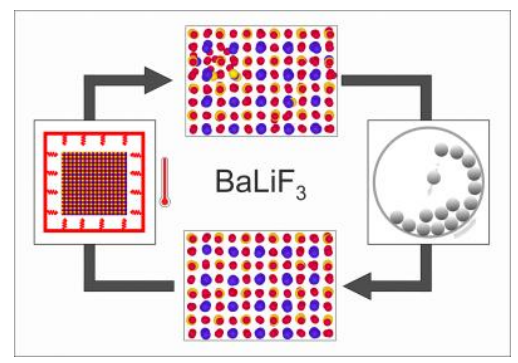

The properties of a functional material are controlled by its defect density. ${ }^{(1-5)}$

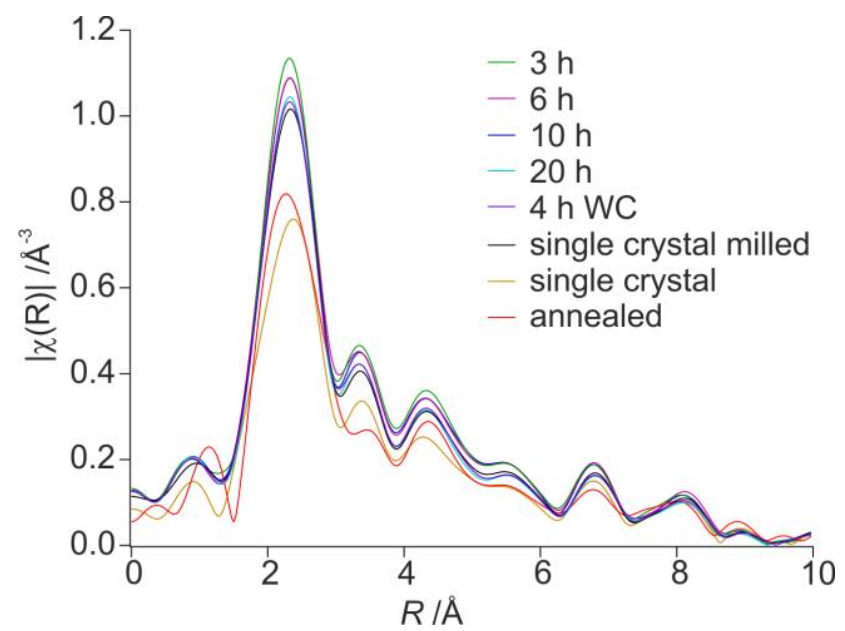

Figure 1. Fourier transforms of $\mathrm{Ba} \mathrm{L}_{\mathrm{III}}$ edge EXAFS measurements of differently prepared $\mathrm{BaLiF}_{3}$ samples.
For example, antisite defects influence the magnetic properties of materials such as double perovskite-structured $\mathrm{Sr}_{2} \mathrm{FeMoO}_{6}{ }^{(6-9)}$, or the $\mathrm{Li}$ ion conductivity in $\mathrm{LiFePO}_{4}{ }^{(10,11)}$. It is known that the preparation method influences the antisite defect density of a material ${ }^{(7,10,11)}$. However, the preparation of materials with a low antisite defect density can be challenging. ${ }^{(6-9)}$

$\mathrm{BaLiF}_{3}$ (perfect) $\quad \mathrm{BaLiF}_{3}$ (antisite defects)
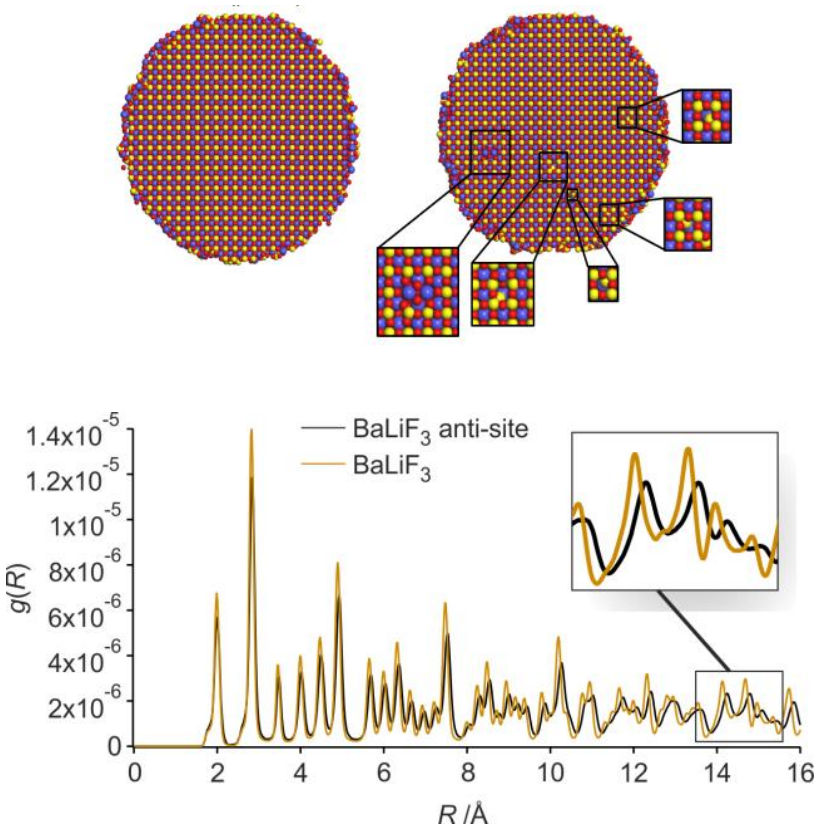

Figure 2. Structures (top) and associated Radial Distribution Functions (bottom) of the model $\mathrm{BaLiF}_{3}$ nanoparticles at $50 \mathrm{~K}$ after the MD runs.

The formation of cation antisite defects was recently investigated in case of perovskite-type $\mathrm{Ba}_{1-x} \mathrm{Sr}_{x} \mathrm{LiF}_{3}$ using molecular dynamics (MD) simulations ${ }^{(12)}$. It was found that the growth of perovskite-structured $\mathrm{BaLiF}_{3}$ goes along with $\mathrm{Ba}$ ions commonly crystallizing onto $\mathrm{Li}$ sites and $\mathrm{Li}$ ions onto $\mathrm{Ba}$ sites. The next crystal layer only grows if most of the wrongly crystallized cation species are replaced by the correct one, which is possible only on the crystal surface (crystallization front). However, a few 


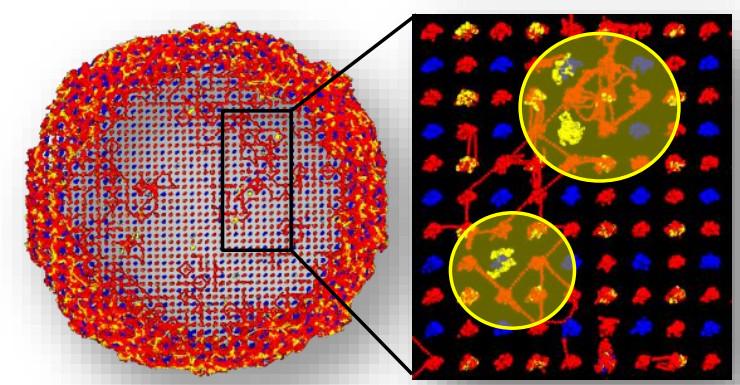

(a)

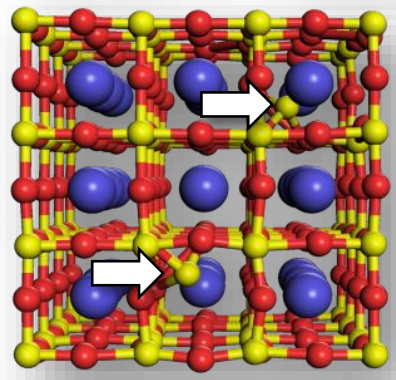

(d)

(b)

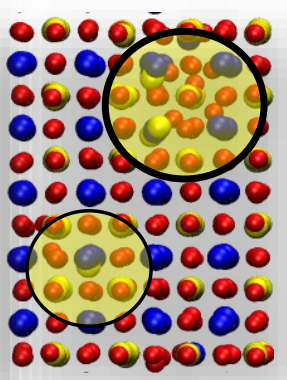

(c)

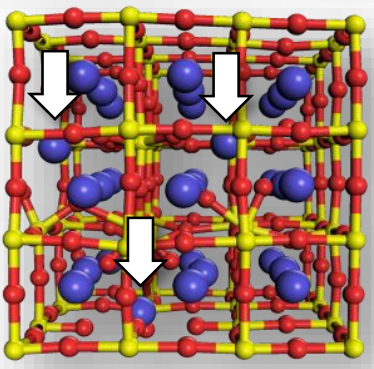

(e)

Figure 3. Atom level model and $\mathrm{F}$ ion mobility of a $\mathrm{BaLiF}_{3}$ nanoparticle with $\mathrm{Ba}-\mathrm{Li}$ antisite defects at $900 \mathrm{~K}$. (a) Image of the whole nanoparticle; snapshots of the atom positions, during the MD simulation, are superimposed to reveal the mobility which is highest near the surface of the nanoparticle and also deep within the nanoparticle around the antisite defects. (b) Enlarged segment of (a) showing more clearly the mobility of the F ions in the vicinity of antisite defects. (c) Segment of the nanoparticle showing the atomistic structure of the complex defect structure and ionic relaxation. (d) Segment showing Li located at Ba sites (positions indicated by white arrows). (e) Segment showing Ba located at Li sites. Barium is colored blue, fluorine is red and lithium is yellow.

wrongly crystallized cations become trapped in the crystal, creating Ba-Li antisite defects. ${ }^{(12)}$

Ball milling is a simple solvent free method of preparing functional materials, with different defect structures compared to thermally synthesized materials. ${ }^{(13,14)}$ It can be used to prepare materials that cannot be prepared thermally, such as solid solutions within miscibility gaps. For example, $\mathrm{Ba}_{1-x} \mathrm{Ca}_{\mathrm{x}} \mathrm{F}_{2}(0.04 \leq \mathrm{x} \leq 0.97)$ segregates to $\mathrm{BaF}_{2}$ and $\mathrm{CaF}_{2}$ under thermal annealing but can be synthesized using ball milling. ${ }^{15,16)}$ Clearly, the mechanisms underpinning ball-milling and thermal annealing are different, which can be exploited as an additional tool for defecttuning functional nanomaterials.

Here we report extended X-ray absorption fine structure (EXAFS) measurements on $\mathrm{BaLiF}_{3}$ nanoparticles, treated post-synthesis, using either ball milling or thermal heating. We find that the two methods lead to different defect densities enabling postsynthesis defect-tuning.

$\mathrm{BaLiF}_{3}$ is first synthesized using either ball milling or a thermal synthesis route. The samples are then characterized using X-ray powder diffraction (XRPD) (see Figure S2) and EXAFS. A postsynthesis step is then performed; the ball milled sample is annealed thermally and the thermally prepared sample is ball milled. The so treated samples were also investigated with EXAFS, to determine how each post processing step changes their crystallinity, i.e. the degree of structural order in the crystallites, and hence the defect density. In parallel, a model $\mathrm{BaLiF}_{3}$ nanoparticle was generated with $1 \% \mathrm{Ba}-\mathrm{Li}$ antisite defects and simulated using MD. The crystallinity of the perfect and defective (model) nanoparticles were then compared. Full details of the experimental and computational methods can be found in supporting information.

The Fourier transform of the $\mathrm{Ba}_{\mathrm{III}}$ edge data (done in a range from $2.3-9.5 \AA^{-1}$ ), thus, the radial distribution function (RDF) from the viewpoint of $\mathrm{Ba}$, of the various $\mathrm{BaLiF}_{3}$ samples is shown in Figure 1.

The ball-milled $\mathrm{BaLiF}_{3}$ samples show narrow lines of high intensity. Conversely, the thermally prepared samples exhibit broadened lines with lower intensity. This indicates that ball-milled $\mathrm{BaLiF}_{3}$ is more crystalline than $\mathrm{BaLiF}_{3}$ prepared thermally and is consistent with a lower $\mathrm{Ba}-\mathrm{Li}$ antisite defect density in the crystallites of ballmilled $\mathrm{BaLiF}_{3}$.

To provide stronger evidence that the crystallinity is influenced by the antisite defect density, the RDF of the model $\mathrm{BaLiF}_{3}$ nanoparticle, with $1 \% \mathrm{Ba}-\mathrm{Li}$ antisite defects, was compared with a perfect (defect free) $\mathrm{BaLiF}_{3}$ model nanoparticle, Figure 2. In accord with our experimental findings, the defective nanoparticle was less crystalline as evidenced by broader and less intense peaks, Figure 2. We also observe an increase in the lattice parameter, which can be attributed to geometric frustration associated with antisite defects expanding the crystal 
structure $^{(16)}$. Such subtle differences in inter-atomic distances are too small to be measured by EXAFS. This demonstrates the value of computer simulation as a complementary technique. The MD simulations also revealed that $\mathrm{Ba}-\mathrm{Li}$ antisite defects increase the mobility of the $\mathrm{F}$ ions in the $\mathrm{BaLiF}_{3}$ nanoparticle, Figure 3. The defect free $\mathrm{BaLiF}_{3}$ reveals no ion mobility at all, in agreement with the work of Zahn et al. ${ }^{(17)}$ who reported a decrease of the Frenkel defect formation energy due to the formation of $\mathrm{Ba}-\mathrm{Li}$ antisite defects. Figure 3 also shows the structural disorder close to the Ba-Li antisite defects.

a)

b)

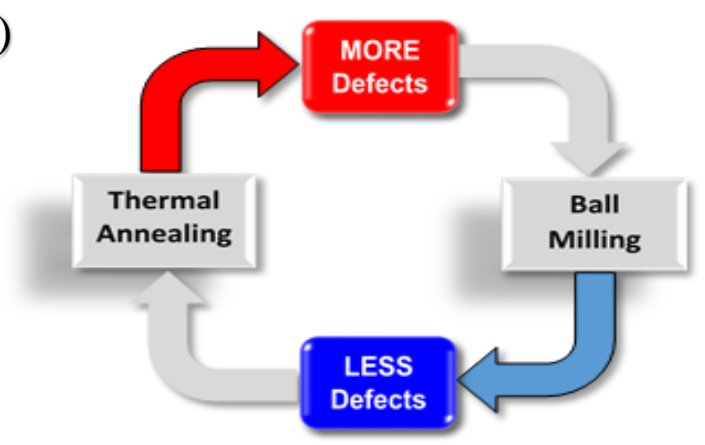

Figure 4. a) Variance of the absorber-scatterer distances of $\mathrm{F}$ ions determined from the EXAFS data of $\mathrm{BaLiF}_{3}$ as a function of milling time. b) A schematic illustrating the process.

To determine whether the defect density of $\mathrm{BaLiF}_{3}$ nanoparticles can be controlled postsynthesis, we ball-milled thermally prepared $\mathrm{BaLiF}_{3}$, and annealed $\mathrm{BaLiF}_{3}$ prepared by ball-milling (see Supporting Information for details).

The variance of the absorber-scatterer distances, $\sigma^{2}$, extracted from the EXAFS data, is shown in Figure 4a for the $\mathrm{F}$ ions in $\mathrm{BaLiF}_{3}$, postprocessed either thermally or ball-milled; we note that a lower $\mathrm{c}(\mathrm{F})$ indicates higher crystallinity and therefore lower defect density. Additional data and information can be found in Supporting Information, Figure S3.

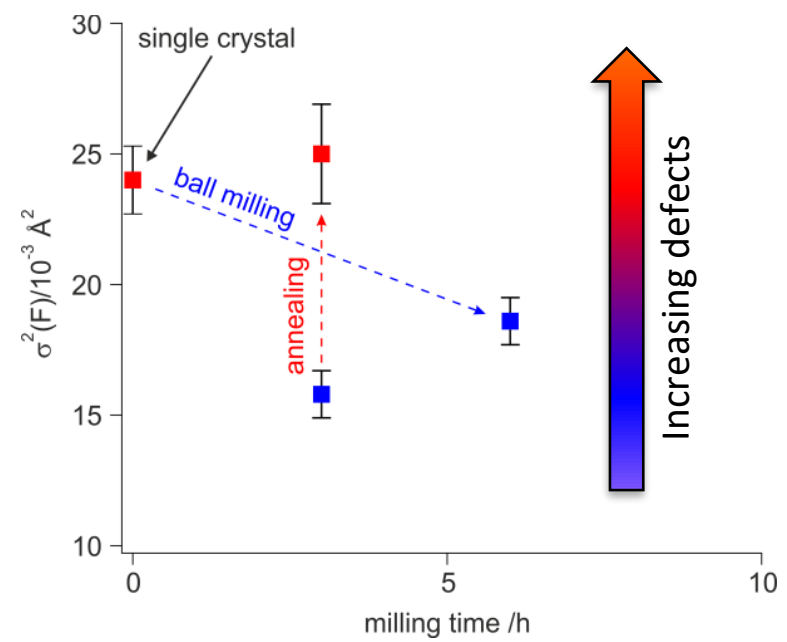

The data shows that ball milling $\mathrm{BaLiF}_{3}$ reduces its defect density. Conversely, thermal annealing, increases its defect density and confirms that the Ba-Li antisite defect density can be tuned postsynthesis: we can increase antisite defects by processing the material thermally or we can reduce the defect density by ball-milling. A schematic describing this process is shown in Figure 4b). A plausible mechanism of the defect repair by ball milling is the exposure of the $\mathrm{Ba}-\mathrm{Li}$ antisite defects to the crystallite surfaces due to the mechanical treatment, where the wrongly crystallized cation is able to leave the site to be replaced by the correct cation species (see Supporting Information for further discussion).

It seems likely that an antisite defect reduction by ball milling can also be observed in other materials which should be investigated in the future.

\section{ASSOCIATED CONTENT}

Supporting Information. XRPD patterns of the samples and further $\sigma^{2}$ data and structural information determined from EXAFS data of all samples (PDF)

The Supporting Information is available free of charge on the ACS Publications website. 


\section{AUTHOR INFORMATION}

\section{Corresponding Author}

Andre Düvel

a.duvel@kent.ac.uk

ORCID: 0000-0002-2393-5453

Dean Sayle

D.C.Sayle@kent.ac.uk

ORCID: 0000-0001-7227-9010

\section{Author Contributions}

All authors contributed equally.

\section{ACKNOWLEDGMENT}

We like to thank A. Feldhoff, J. Caro and E. McCabe for access to their X-Ray diffractometers. We thank Diamond Light Source for the award of beam time on B18 as part of the Energy Materials Block Allocation Group under proposal SP14239. A.D. is grateful for financial support by the German Research Foundation (DFG), DU 1668 1-1/2. We would also like to thank the UK Materials and Molecular Modelling Hub for computational ressources which are partially funded by EPSRC (EP/P020194).

\section{REFERENCES}

(1) Queisser, H.J; Haller, E.E. Defects in Semiconductors: Some Fatal, Some Vital, Science 1998, 281, 945-950.

(2) Zhao, M.; Pan, W.; Wan, C.; Qu, Z.; Li, Z.; Yang, J. Defect Engineering in Development of Low Thermal Conductivity Materials: A Review. J. Eur. Ceram. Soc. 2017, 37, 1-13.

(3) Gfroerer, T. H.; Zhang, Y.; Wanlass, M. W. An Extended Defect as a Sensor for Free Carrier Diffusion in a Semiconductor. Appl. Phys. Lett. 2013, 102, 012114.

(4) Ning, S.; Zhan, P.; Wang, W.; Zhang, Z. Defects-Driven Ferromagnetism in Undoped Dilute Magnetic Oxides: A Review. J. Mater. Sci. Technol. 2015, 31, 969-978.

(5) Yamada, Y.; Endo, M.; Wakamiya, A.; Kanemitsu, Y. Spontaneous Defect Annihilation in $\mathrm{CH}_{3} \mathrm{NH}_{3} \mathrm{PbI}_{3}$ Thin Films at Room Temperature Revealed by Time-Resolved Photoluminescence Spectroscopy. J. Phys. Chem. Lett. 2015, 6, 482-486.
(6) Sarma, D.D.; Sampathkumaran, E.V.; Ray, S.; Nagarajan, R.; Majumdar, S.; Kumar, A.; Nalini, G.; Guru Row, T.N. Magnetoresistance in Ordered and Disordered Double Perovskite Oxide, $\mathrm{Sr}_{2} \mathrm{FeMoO}_{6}$. Solid State Commun. 2000, 114, 465-468.

(7) Balcells, Ll.; Navarro, J.; Roig, A.; Martinez, B.; Fontcuberta, J. Cationic Ordering Control of Magnetization in $\mathrm{Sr}_{2} \mathrm{FeMoO}_{6}$ Double Perovskite. Appl. Phys. Lett. 2001, 78, 781-783.

(8) Singh, V.N.; Majumdar, P. Antisite Domains in Double Perovskite Ferromagnets: Impact on Magnetotransport and Half-Metallicity. EPL 2011, 94, 47004.

(9) Saloaro, M.; Hoffmann, M.; Adeagbo, W.A.; Granroth, S.; Deniz, H.; Palonen, H.; Huhtinen, H.; Majumdar, S.; Laukkanen, P.; Hergert, W.; Ernst, A.; Paturi, P. Towards Versatile $\mathrm{Sr}_{2} \mathrm{FeMoO}_{6}$-Based Spintronics by Exploiting Nanoscale Defects. ACS Appl. Mater. Inter. 2016, 8, 20440-20447.

(10) Chen, J.; Graetz, J. Study of Antisite Defects in Hydrothermally Prepared $\mathrm{LiFePO}_{4}$ by in Situ X-ray Diffraction. ACS Appl. Mater. Inter. 2011, 3, 1380-1384.

(11) Paolella, A.; Bertoni, G.; Hovington, P.; Feng, Z.; Flacau, R.; Prato, M.; Colombo, M.; Marras, S.; Manna, L.; Turner, S.; van Tendeloo, G.; Guerfi, A.; Demopoulos, G. P.; Zaghib, K. Cation Exchange Mediated Elimination of the Fe-antisites in the Hydrothermal Synthesis of $\mathrm{LiFePO}_{4}$. Nano Energy 2015, 16, 256-267.

(12) Düvel, A.; Morgan, L.M.; Chandran, C.V.; Heitjans, P.; Sayle, D.C. Formation and Elimination of Anti-Site Defects During Crystallization in Perovskite Ba1-x $\mathrm{Sr}_{x} \mathrm{LiF}_{3}$. Cryst. Growth Des. 2018, 18, 2093 2099.

(13) Šepelák, V.; Becker, S.M.; Bergmann, I.; Indris, S.; Scheuermann, M.; Feldhoff, A.; Kübel, C.; Bruns, M.; Stürzl, N.; Ulrich, A.S.; Ghafari, M.; Hahn, H.; Grey, C.P.; Becker, K.D.; Heitjans, P. Nonequilibrium Structure of $\mathrm{Zn}_{2} \mathrm{SnO}_{4}$ Spinel Nanoparticles. J. Mater. Chem. 2012, 22, 3117-3126.

(14) Šepelák, V.; Düvel, A.; Wilkening, M.; Becker, K.-D.; Heitjans, P. Mechanochemical Reactions and Syntheses of Oxides. Chem. Soc. Rev. 2013, 42, 7507-7520.

(15) Düvel, A.; Ruprecht, B.; Heitjans, P.; Wilkening, M. Mixed Alkaline-Earth Effect in the Metastable Anion Conductor $\mathrm{Ba}_{1-x} \mathrm{Ca}_{x} \mathrm{~F}_{2}(0 \leq$ $\mathrm{x} \leq 1$ ): Correlating Long-Range Ion Transport with Local Structures Revealed by Ultrafast ${ }^{19} \mathrm{~F}$ MAS NMR. J. Phys. Chem. C 2011, 115, 23784-23789.

(16) Düvel, A.; Heitjans, P.; Fedorov, P.; Scholz, G.; Cibin, G. Chadwick, A.V.; Pickup, D.M.; Ramos, S.; Sayle, L.W.L.; Sayle, E.K.; Sayle, T.X.T.; Sayle, D.C. Is Geometric Frustration-Induced Disorder a Recipe for High Ionic Conductivity? J. Am. Chem. Soc. 2017, 139, 5842-5848.

(17) Zahn, D.; Herrmann, S.; and Heitjans, P. On the Mechanisms of Ionic Conductivity in $\mathrm{BaLiF}_{3}$ : A Molecular Dynamics Study. Phys. Chem. Chem. Phys. 2011, 13, 21492-21495. 